\section{Cureus}

\title{
Link Between Non-Alcoholic Fatty Liver Disease and Atrial Fibrillation: A Systematic Review and Meta-Analysis
}

\author{
Abdul M. Minhas ${ }^{1}$, Muhammad S. Usman ${ }^{2}$, Muhammad S. Khan ${ }^{3}$, Kaneez Fatima ${ }^{4}$,
} Muhammad A. Mangi ${ }^{5}$, Michael A. Illovsky ${ }^{6}$

1. Internal Medicine, Orange Park Medical Center, Orange Park, USA 2. Internal Medicine, Civil Hospital Karachi, Dow University of Health Sciences, Karachi, Pakistan, Karachi, PAK 3. Internal Medicine, John H Stroger J. Hospital of Cook County, Chicago, USA 4. Internal Medicine, Civil Hospital; Dow University of Health Sciences, Karachi, PAK 5. Internal Medicine, Orange Park Medical Center 6. First Coast Cardiovascular Institute, Orange Park, Fl, Usa

$\square$ Corresponding author: Muhammad S. Khan, shahzebkhan@gmail.com Disclosures can be found in Additional Information at the end of the article

\section{Abstract}

Association between non-alcoholic fatty liver disease (NAFLD) and various cardiovascular diseases has been demonstrated previously. Recent clinical studies have shown that increased circulating levels of $\gamma$ glutamyl transpeptidase and liver transaminase, markers which are elevated in NAFLD, increase the risk of new-onset atrial fibrillation. We conducted a systematic review and meta-analysis of the available evidence to establish the possible association of increased chances of atrial fibrillation in patients with NAFLD. We extensively searched the PubMed, EMBASE, Cochrane Library, ISI Web of Science and Scopus databases to identify all possible studies that investigated the possible association of NAFLD with atrial fibrillation. Random effect models were used to pool the data between NAFLD and non-NAFLD group. ${ }^{2}$ testing was done to assess the heterogeneity of the included studies. Our primary outcome was atrial fibrillation. A total of three studies including 1044 patients in the NAFLD arm and 1016 in the placebo arm were included. On pooled analysis, it was observed that patients with NAFLD had 2.5 times significantly higher chance $(\mathrm{OR}=2.47, \mathrm{CI}=1.30-4.66, \mathrm{p}=0.005)$ of developing new-onset atrial fibrillation. Our meta-analysis identifies the paucity of high-quality evidence regarding the association between NAFLD and atrial fibrillation. More studies are needed to confirm the link between NAFLD and atrial fibrillation.

Categories: Cardiology, Family/General Practice, Public Health Keywords: atrial fibrillation, liver disease, nafld, meta-analysis

Received 03/11/2017 Review began 03/30/2017 Review ended 04/01/2017 Published 04/06/2017

\section{(c) Copyright 2017}

Minhas et al. This is an open access article distributed under the terms of the Creative Commons Attribution License CC-BY 3.0., which permits unrestricted use, distribution, and reproduction in any medium, provided the original author and source are credited.

\section{Introduction And Background}

Non-alcoholic fatty liver disease (NAFLD) is the leading cause of chronic liver disease in many western countries [1-2]. Approximately $30 \%$ of the adult population in these countries are afflicted with NAFLD, and the prevalence further increases to 70-90\% in those with obesity or diabetes [3]. In the past, a link between NAFLD and cardiovascular diseases has been demonstrated. Furthermore, recent clinical studies have shown that increased circulating levels of gamma-glutamyl transpeptidase (GGT) and liver transaminase increase the risk of new-onset atrial fibrillation (AF) [4-5]. Both these enzymes are known to be elevated in NAFLD [6]. This suggests that NAFLD could be a predictor of AF.

An association between the two disorders could have important clinical implications for 
patients with NAFLD, including different treatment approaches, along with an emphasis on prophylaxis against AF. The above information raises an important question: "What are the chances that a patient diagnosed with non-alcoholic fatty liver disease will also develop AF?" Using this question as our hypothesis, we conducted a systematic review and meta-analysis of relevant studies.

\section{Review}

\section{Methods}

Data Sources and Search Strategy

A systemic literature search was conducted using PubMed, EMBASE, Cochrane Library, ISI Web of Science, and Scopus using the search string (non-alcoholic fatty liver disease OR NAFLD OR non-alcoholic steatohepatitis OR non-alcoholic steatosis) AND (atrial fibrillation OR auricular fibrillation OR atrial flutter). Each database was searched from its inception to November 2016. Furthermore, references and citations of each article were manually screened to identify further relevant articles. All the results were transferred to EndNote and duplicate articles were identified and removed.

\section{Inclusion and Exclusion Criteria}

Our selection criteria included observational studies investigating the association between NAFLD and AF. Studies which employed well-established criteria for the diagnosis of NAFLD and AF were considered only. Furthermore, only those studies were considered in which the participants did not have a history of myocardial infarction at baseline. Our exclusion criteria included interventional studies, review articles, case reports, case series, book chapters, editorials, and animal studies. Articles dealing with alcoholic fatty liver disease and those concerned with non-atrial arrhythmias were excluded as well.

\section{Data Extraction and Assessment of Study Quality}

All articles obtained from the searches were screened by two reviewers, who were blinded to the findings of each other. Documents were selected only if they strictly matched the eligibility criteria. The articles were first shortlisted on the basis of titles and abstracts. Then, full texts were read to assess relevance. Any discrepancies during this process were solved by discussion until a consensus was reached. If a consensus could not be reached, a third reviewer was consulted.

Data from the included studies were extracted onto excel sheets by two independent investigators. Patient characteristics (authors, type of studies, the number of patients, year of publication, age, gender, diagnostic modality of NAFLD, AF assessment, outcome, mean follow-up time, adjustment of covariates, and results) were recorded. The Newcastle-Ottawa scale was used to assess the quality of the studies selected for meta-analysis [7]: a maximum of nine points to each cohort study (four for quality of selection, two for comparability, and three for quality of outcome and adequacy of follow-up) and a maximum score of 10 points to the cross-sectional study (five for quality of selection, two for comparability, and three for quality of outcome). Researches with a score of greater than seven are considered to have a good methodological quality and low bias.

\section{Statistical Analysis}

The association between NAFLD and AF was studied using odds ratios (OR). The heterogeneity 
between studies was approximated by using the Higgins I2 test (I2 < 50\% was considered acceptable) [8]. The data from component studies were pooled using a random effects model. Furthermore, a forest plot was created to visually assess the OR values and their corresponding 95\% confidence intervals across studies. Publication bias was assessed using a contour funnel plot and Begg's rank correlation test [9].

\section{Results}

\section{Identification of Eligible Studies}

In total, 344 potentially relevant abstracts were identified. After duplicates were removed, 63 unique abstracts remained. After examining the full-text publications, 21 publications seemed to meet the inclusion criteria. Of these, 18 were excluded for the following reasons: no available data on the outcome, review articles, alcohol use, non-atrial arrhythmias, and the diagnosis of NAFLD with liver enzymes. Finally, the remaining three studies to existing data met our selection criteria and were included in the meta-analysis.

The detailed search strategy is outlined using PRISMA flow sheet in Figure 1.
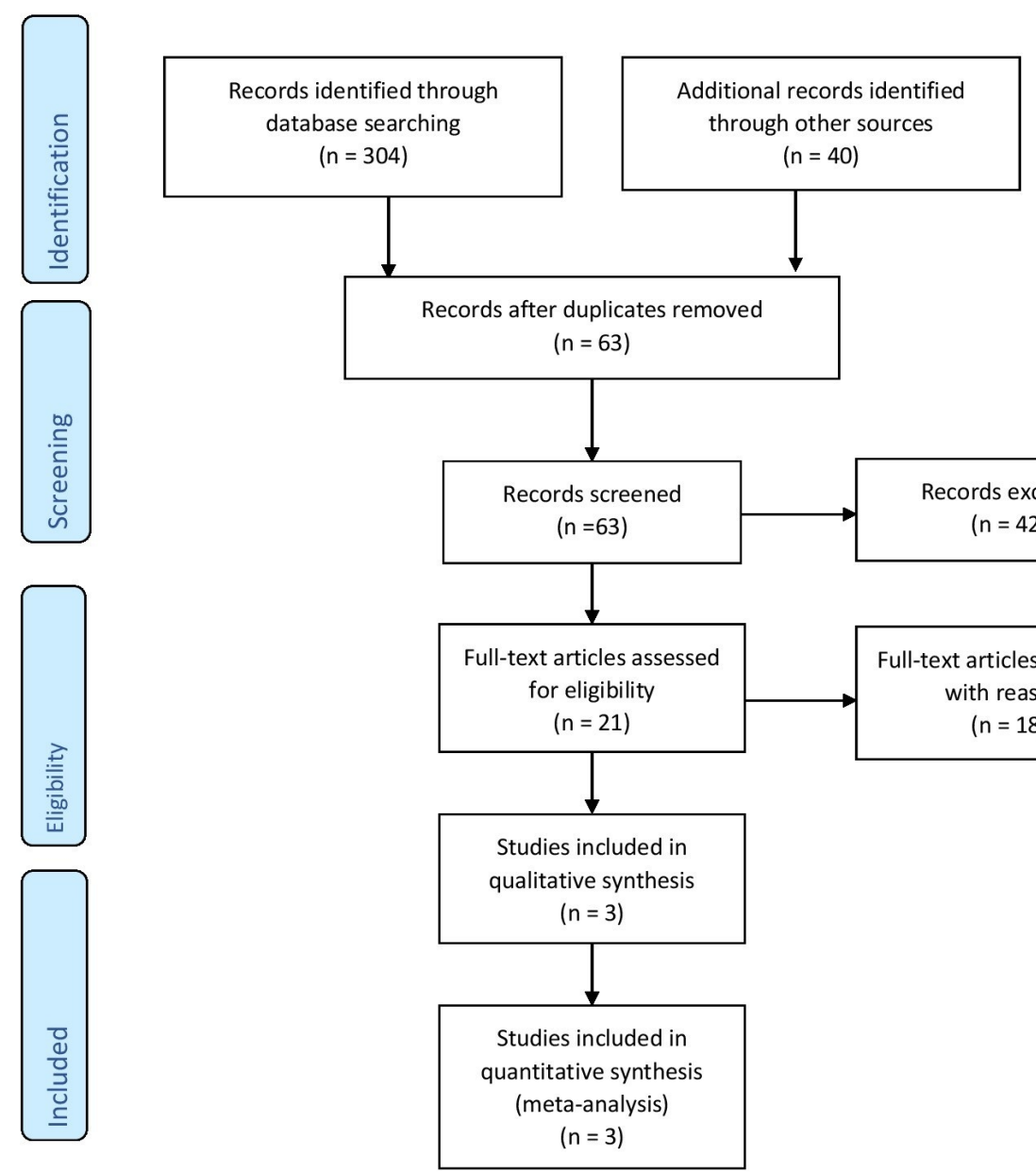

\section{FIGURE 1: PRISMA flow sheet}

Study Characteristics 


\section{Cureus}

Three studies ( $n=1044$ in NAFLD group and $n=1016$ in non-NAFLD group) were selected for meta-analysis [10-12]. The characteristics of these studies are summarized in Table 1. Two of the studies were prospective cohorts [10-11] while the other was a cross-sectional study [12]. All the included studies were published in the previous four years and were single-center studies. The method of assessment of NAFLD and AF was consistent across all studies. All the studies were of high methodological quality. Table 2 and Table 3 show a detailed breakdown of the quality assessment of each study.

\begin{tabular}{|c|c|c|c|c|c|c|c|c|c|}
\hline Study & Population & $\begin{array}{l}\text { Mean Age } \\
\text { (NAFLD/No- } \\
\text { NAFLD) }\end{array}$ & $\begin{array}{l}\text { Males \% } \\
\text { (NAFLD/No- } \\
\text { NAFLD) }\end{array}$ & NAFLD Assessment & AF Assessment & $\begin{array}{l}\text { Outcome } \\
\text { (AF/Total) }\end{array}$ & $\begin{array}{l}\text { Mean } \\
\text { Follow- } \\
\text { up } \\
\text { Time }\end{array}$ & $\begin{array}{l}\text { Adjustment of } \\
\text { Covariates }\end{array}$ & Result \\
\hline $\begin{array}{l}\text { Karajamaki } \\
\text { AJ, } 2015 \\
\text { Finland } \\
\text { Prospective } \\
\text { Cohort } \\
\text { Study }\end{array}$ & $\begin{array}{l}\text { Total; } 958 \\
\text { NAFLD: } \\
249 \text { Non- } \\
\text { NAFLD: } \\
709\end{array}$ & $52 \pm 6 / 51 \pm 6$ & $58 / 43$ & $\begin{array}{l}\text { Hepatic } \\
\text { ultrasonography by a } \\
\text { radiologist with 10- } \\
\text { year experience }\end{array}$ & $\begin{array}{l}\text { Based on standard } \\
\text { 12-lead resting ECG. } \\
\text { (noted in medical } \\
\text { records) }\end{array}$ & $\begin{array}{l}\text { NAFLD: } \\
37 / 249 \\
\text { Non- } \\
\text { NAFLD: } \\
\text { 56/709 }\end{array}$ & $\begin{array}{l}16.3 \\
\text { years }\end{array}$ & $\begin{array}{l}\text { Age, sex, } \\
\text { diabetes } \\
\text { mellitus, BMI, } \\
\text { waist } \\
\text { circumference, } \\
\text { smoking, serum } \\
\text { ALT, systolic } \\
\text { BP, Left atrial } \\
\text { diameter, ANP, } \\
\text { CAD and hs- } \\
\text { CRP }\end{array}$ & $\begin{array}{l}\text { COR } \\
1.96 \\
(1.29- \\
2.97)\end{array}$ \\
\hline $\begin{array}{l}\text { Targher G, } \\
2013 \text { Italy } \\
\text { Prospective } \\
\text { Cohort } \\
\text { Study }\end{array}$ & $\begin{array}{l}\text { Total: } 400 \\
\text { NAFLD: } \\
281 \text { Non- } \\
\text { NAFLD: } \\
119\end{array}$ & $63 \pm 9 / 64 \pm 9$ & $59.4 / 57.1$ & $\begin{array}{l}\text { Hepatic } \\
\text { ultrasonography } \\
\text { performed in all } \\
\text { patients by an } \\
\text { experienced } \\
\text { radiologist, who was } \\
\text { blind to the } \\
\text { participants' details }\end{array}$ & $\begin{array}{l}\text { Based on a } \\
\text { standard 12-lead } \\
\text { resting ECG. (noted in } \\
\text { routine examination, } \\
\text { or in medical records) }\end{array}$ & $\begin{array}{l}\text { NAFLD: } \\
38 / 281 \\
\text { Non- } \\
\text { NAFLD: } \\
4 / 119\end{array}$ & $\begin{array}{c}10 \\
\text { years }\end{array}$ & $\begin{array}{l}\text { Age, sex, } \\
\text { hypertension, } \\
\text { LVH status and } \\
\text { PR interval }\end{array}$ & $\begin{array}{l}\text { COR } \\
4.49 \\
(1.6- \\
12.9)\end{array}$ \\
\hline $\begin{array}{l}\text { Targher G, } \\
2013 \text { Italy } \\
\text { Cross- } \\
\text { Sectional } \\
\text { Study }\end{array}$ & $\begin{array}{l}\text { Total: } 702 \\
\text { NAFLD: } \\
514 \text { Non- } \\
\text { NAFLD: } \\
188\end{array}$ & $65 \pm 13 / 68 \pm 14$ & $55.6 / 49.5$ & $\begin{array}{l}\text { Hepatic } \\
\text { ultrasonography was } \\
\text { performed in all } \\
\text { patients by } \\
\text { experienced } \\
\text { radiologists, who } \\
\text { were blinded to } \\
\text { subjects' } \\
\text { characteristics }\end{array}$ & $\begin{array}{l}\text { Based on a standard } \\
\text { 12-lead ECG done } \\
\text { during hospital stay; } \\
\text { or from medical } \\
\text { history. (noted during } \\
\text { hospital stay, or in } \\
\text { medical records) }\end{array}$ & $\begin{array}{l}\text { NAFLD: } \\
\text { 75/514 } \\
\text { Non- } \\
\text { NAFLD: } \\
\text { 10/188 }\end{array}$ & - & $\begin{array}{l}\text { Age, sex, } \\
\text { diabetes } \\
\text { duration, } \\
\text { HbA1c, LVH } \\
\text { status, IHD, } \\
\text { VHD and HF }\end{array}$ & $\begin{array}{l}\text { COR } \\
3.04 \\
(1.54- \\
6.02)\end{array}$ \\
\hline
\end{tabular}

\section{TABLE 1: Characteristics of the three included studies}

ALT: Alanine aminotransferase; ANP: Atrial natriuretic peptide; BMI: Body mass index; BP: Blood pressure; CAD: Coronary artery disease; COR: Crude odds ratio; ECG: Electrocardiogram; HF: Heart failure; hs-CRP: High sensitivity C- reactive protein; IHD: Ischemic heart disease; LVH: Left ventricular hypertrophy; NAFLD: Non-alcoholic fatty liver disease; VHD: Valvular heart disease. 


\section{Cureus}

\section{Newcastle Ottawa Quality Assessment Scale for Cohort Studies}

Karajamaki AJ, et al., Targher G, et al., 2015

Selection

1) Representativeness of cohort

${ }^{*}(\mathrm{~A})$

2) Selection of non-exposed cohort

*(A)

${ }^{*}(\mathrm{~A})$

3) Ascertainment of exposure

*(A)

4) Demonstration that outcome of interest was not present at the start of the study

Comparability

1) Comparability of cohorts on the basis of design or analysis

Outcome

1) Assessment of outcome

*(B)

2) Was follow-up long enough for outcomes to occur?

3) Adequacy of follow-up cohorts

*(A)

\section{TABLE 2: Quality assessment of cohort studies}

${ }^{*}(A),{ }^{*}(B),{ }^{* *}(A+B):$ refer to 'Newcastle Ottawa Quality Assessment Scale for Cohort Studies' [7] 


\section{Cureus}

\section{Modified Newcastle Ottawa Quality Assessment Scale for Cross-Sectional Studies}

Targher G, et al., 2013

Selection

1) Representativeness of sample

2) Sample size

3) Non-respondents

4) Ascertainment of exposure

Comparability

1) Subjects are comparable on the basis of study design or analysis

Outcome

1) Assessment of outcome

2) Statistical test

Total Score

$9 / 10$

\section{TABLE 3: Quality assessment of the cross-sectional study}

${ }^{*}(\mathrm{~A}),-(\mathrm{B}),{ }^{* *}(\mathrm{~A}),{ }^{* *}(\mathrm{~A}+\mathrm{B}),{ }^{* *}(\mathrm{~B})$ : refer to 'Modified Newcastle Ottawa Quality Assessment Scale for Cross-Sectional Studies' [7]

Meta-Analysis of Primary Outcomes

The pooled ORs showed that patients with NAFLD were around 2.5 times more likely to develop new-onset $\mathrm{AF}(\mathrm{OR}=2.47,95 \% \mathrm{CI}=1.30-4.66, \mathrm{p}=0.005)$. A forest plot outlining the metaanalysis is shown in Figure 2. We found no evidence of publication bias (Figure 3). 


\section{Cureus}

Study

ID

OR $(95 \% \mathrm{Cl})$

Karajamaki AJ (2016)

Targher G. (2013)

Targher 5 (2013)

Overall (l-squared $=60.9 \%, p=0.078$ )

NOTE: Weights are from random effects analysis

.0775

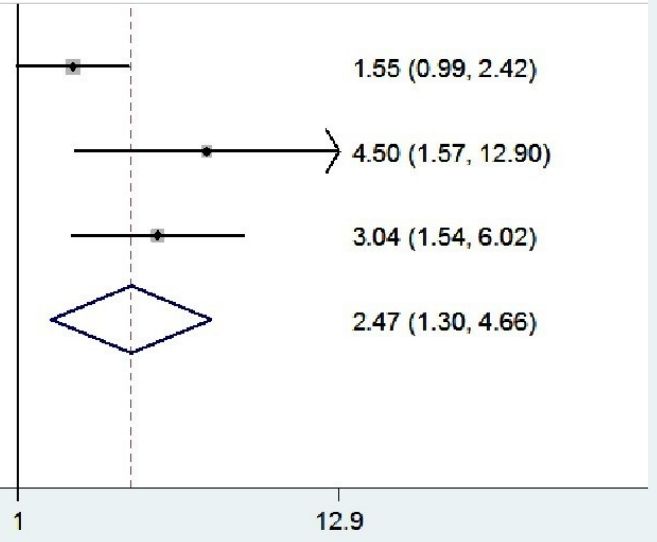

12.9

\section{FIGURE 2: Forest plot summarizing the pooling of studies}

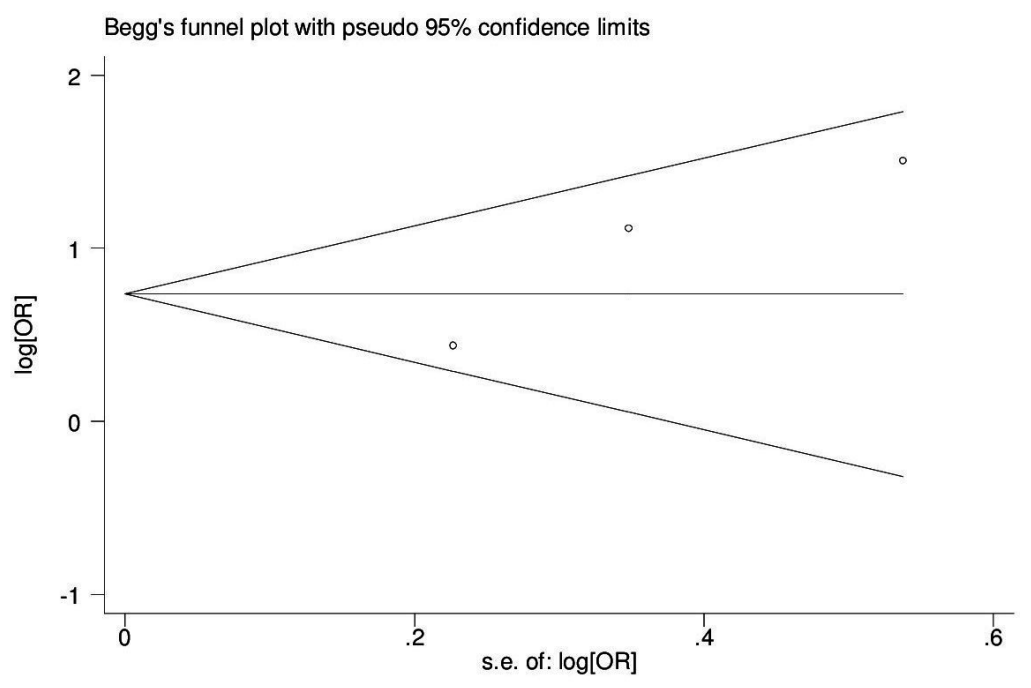

\section{FIGURE 3: Begg graph for publication bias}

s.e.: standard error

\section{Discussion}

To the best of our knowledge, this is the first systematic review and meta-analysis to study the correlation between NAFLD and AF. Our findings indicate that patients with NAFLD have a statistically significant increased risk of developing AF. The three studies included in our metaanalysis report ORs that, while somewhat variable in magnitude, indicate a positive correlation between NAFLD and AF. Furthermore, in all studies, the association persists and remains statistically significant across a range of subgroup analyses. Although observational studies 
cannot prove causation, these three studies meet many of the Hill's criteria for causation [13]. First, the association between NAFLD and AF is statistically significant and most likely not by chance. Second, consistency is seen across the studies - the relationship has been noted in different groups of people and in different locations. Third, a clear temporal association is seen in two of the studies [10-11], where NALFD precedes the onset of AF. Fourth, there is a biological plausibility explaining how NAFLD could lead to AF. All these factors indicate possible causation and set the stage for future research to prove whether NAFLD actually causes AF.

A few hypothetical mechanisms by which NAFLD might lead to AF have been proposed. First, there is evidence that NAFLD independently causes systemic inflammation. The accumulation of fat within hepatocytes increases oxidative stress, which in turn causes the release of proinflammatory cytokines [14]. This escalates NAFLD to non-alcoholic steatohepatitis (NASH), and may also lead to systemic inflammation [15-16]. Inflammation is known to induce atrial fibrillation [17-18]. To make matters worse, AF seems to generate and sustain a proinflammatory environment, leading to a vicious cycle. Second, NAFLD has been shown to be associated with autonomic dysfunction [19-20]. The irregular sympathovagal stimulation in this condition is associated with an increased risk of atrial fibrillation [21-22] and could be the causal link between NAFLD and AF. Third, NAFLD has been shown to be an independent risk factor for cardiac diastolic dysfunction [23-24], which in turn has been reported to aggravate atrial fibrillation [25-26].

However, the results of our meta-analysis are limited by many factors. The total number of participants in our analysis was only 2,060 which are much less than the amount seen in other meta-analyses [27-28]. Also, the evidence was based on a pooled analysis of observational studies which is limited by the study design and presence of confounders. Furthermore, in two of the studies, all the participants were diabetic - this sample is not a valid indicator of the general population. Another limitation is the fact that included studies did not observe how the risk of AF varied with increasing amounts of fatty accumulation in the liver.

\section{Conclusions}

Our meta-analysis identifies the paucity of high-quality evidence regarding the association between NAFLD and AF. More studies are needed to confirm the link between NAFLD and AF.

\section{Additional Information \\ Disclosures}

Conflicts of interest: In compliance with the ICMJE uniform disclosure form, all authors declare the following: Payment/services info: All authors have declared that no financial support was received from any organization for the submitted work. Financial relationships: All authors have declared that they have no financial relationships at present or within the previous three years with any organizations that might have an interest in the submitted work. Other relationships: All authors have declared that there are no other relationships or activities that could appear to have influenced the submitted work.

\section{References}

1. Anstee QM, McPherson S, Day CP: How big a problem is non-alcoholic fatty liver disease . BMJ. 2011, 343:d3897. 10.1136/bmj.d3897

2. Clark JM, Brancati FL, Diehl AM: The prevalence and etiology of elevated aminotransferase levels in the United States. Am J Gastroenterol. 2003, 98:960-967. 10.1111/j.15720241.2003.07486.x

3. Targher GT, Day CP, Bonora E: Risk of cardiovascular disease in patients with nonalcoholic 
fatty liver disease. N Engl J Med. 2010, 363:1341-1350. 10.1056/NEJMra0912063

4. Alonso A, Misialek JR, Amiin MA, et al.: Circulating levels of liver enzymes and incidence of atrial fibrillation: the atherosclerosis risk in communities cohort. Heart. 2014, 100:1511-1516. 10.1136/heartjnl-2014-305756

5. Sinner MF, Wang N, Fox CS, et al.: Relation of circulating liver transaminase concentrations to risk of new-onset atrial fibrillation. Am J Cardiol. 2013, 111:219-224.

10.1016/j.amjcard.2012.09.021

6. Ghouri N, Preiss D, Sattar N: Liver enzymes, nonalcoholic fatty liver disease, and incident cardiovascular disease: a narrative review and clinical perspective of prospective data. Hepatology. 2010, 52:1156-61. 10.1002/hep.23789

7. The Newcastle-Ottawa Scale (NOS) for assessing the quality of nonrandomised studies in meta-analyses. (2014). Accessed: March 15, 2017: http://www.ohri.ca/programs/clinical_epidemiology/oxford.asp.

8. Higgins JP, Thompson SG, Deeks JJ, et al.: Measuring inconsistency in meta-analyses . BMJ. 2003, 327:557-560. 10.1136/bmj.327.7414.557

9. Begg CB, Mazumdar M: Operating characteristics of a rank correlation test for publication bias. Biometrics. 1994, 50:1088-101. 10.2307/2533446

10. Käräjämäki AJ, Pätsi OP, Savolainen M, et al.: Non-alcoholic fatty liver disease as a predictor of atrial fibrillation in middle-aged population (OPERA Study). PLoS One. 2015, 10:e0142937. 10.1371/journal.pone.0142937

11. Targher G, Valbusa F, Bonapace S, et al.: Non-alcoholic fatty liver disease is associated with an increased incidence of atrial fibrillation in patients with type 2 diabetes. PLoS One. 2013, 8:e57183. 10.1371/journal.pone.0057183

12. Targher G, Mantovani A, Pichiri I, et al.: Non-alcoholic fatty liver disease is associated with an increased prevalence of atrial fibrillation in hospitalized patients with type 2 diabetes. Clin Sci (Lond). 2013, 125:301-309. 10.1042/CS20130036

13. Hill AB: The environment and disease: association or causation. Proc R Soc Med. 1965, 58:295-300.

14. Ndumele CE, Nasir K, Conceiçao RD, et al.: Hepatic steatosis, obesity, and the metabolic syndrome are independently and additively associated with increased systemic inflammation. Arterioscler Thromb Vasc Biol. 2011, 31:1927-1932. 10.1161/ATVBAHA.111.228262

15. Verdelho Machado M, Cortez-Pinto H: Non-alcoholic fatty liver disease: what the clinician needs to know. World J Gastroenterol. 2014, 20:12956-12980. 10.3748/wjg.v20.i36.12956

16. Furukawa S, Fujita T, Shimabukoro M, et al.: Increased oxidative stress in obesity and its impact on metabolic syndrome. J Clin Invest. 2004, 114:1752-1761. 10.1172/JCI21625

17. Harada M, Van Wagoner DR, Nattel S: Role of inflammation in atrial fibrillation pathophysiology and management. Circ J. 2015, 79:495-502. 10.1253/circj.CJ-15-0138

18. Aviles RJ, Martin DO, Apperson-Hansen C, et al.: Inflammation as a risk factor for atrial fibrillation. Circulation. 2003, 108:3006-3010. 10.1161/01.CIR.0000103131.70301.4F

19. Liu YC, Hung CS, Wu YW, et al.: Influence of non-alcoholic fatty liver disease on autonomic changes evaluated by the time domain, frequency domain, and symbolic dynamics of heart rate variability. PLoS One. 2013, 8:e61803. 10.1371/journal.pone.0061803

20. Sun W, Zhang D, Sun J, et al.: Association between non-alcoholic fatty liver disease and autonomic dysfunction in a Chinese population. QJM. 2015, 108:617-624.

10.1093/qjmed/hcv006

21. Perkiömäki J, Ukkola O, Kiviniemi A, et al.: Heart rate variability findings as a predictor of atrial fibrillation in middle-aged population. J Cardiovasc Electrophysiol. 2014, 25:719-724. 10.1111/jce.12402

22. Shen MJ, Zipes DP: Role of the autonomic nervous system in modulating cardiac arrhythmias . Circ Res. 2014, 114:1004-1021. 10.1161/CIRCRESAHA.113.302549

23. Granér M, Nyman K, Siren R, et al.: Ectopic fat depots and left ventricular function in nondiabetic men with nonalcoholic fatty liver disease. Circ Cardiovasc Imaging. 2014, 8:e001979. 10.1161/CIRCIMAGING.114.001979

24. Fotbolcu H, Yakar T, Duman D, et al.: Impairment of the left ventricular systolic and diastolic function in patients with non-alcoholic fatty liver disease. Cardiol J. 2010, 17:457-463.

25. Tsang TS, Gersh BJ, Appleton CP, et al.: Left ventricular diastolic dysfunction as a predictor of the first diagnosed nonvalvular atrial fibrillation in 840 elderly men and women. J Am Coll Cardiol. 2002, 40:1636-1644. 10.1016/S0735-1097(02)02373-2 


\section{Cureus}

26. Nagarakanti R, Ezekowitz M: Diastolic dysfunction and atrial fibrillation. J Interv Card Electrophysiol. 2008, 22:111-118. 10.1007/s10840-008-9203-8

27. Du X, Liu L, Song W, et al.: Association between gout and erectile dysfunction: a systematic review and meta-analysis. PLoS One. 2016, 11:e0168784. 10.1371/journal.pone.0168784

28. Luni FK, Riaz H, Khan AR, et al.: Clinical outcomes associated with per-operative discontinuation of aspirin in patients with coronary artery disease: a systematic review and meta-analysis. Catheter Cardiovasc Interv. 2016, 10.1002/ccd.26807 